ECOLOGY

\title{
Resurrected seeds to track evolution
}

\section{US bank created to monitor plants' response to climate change.}

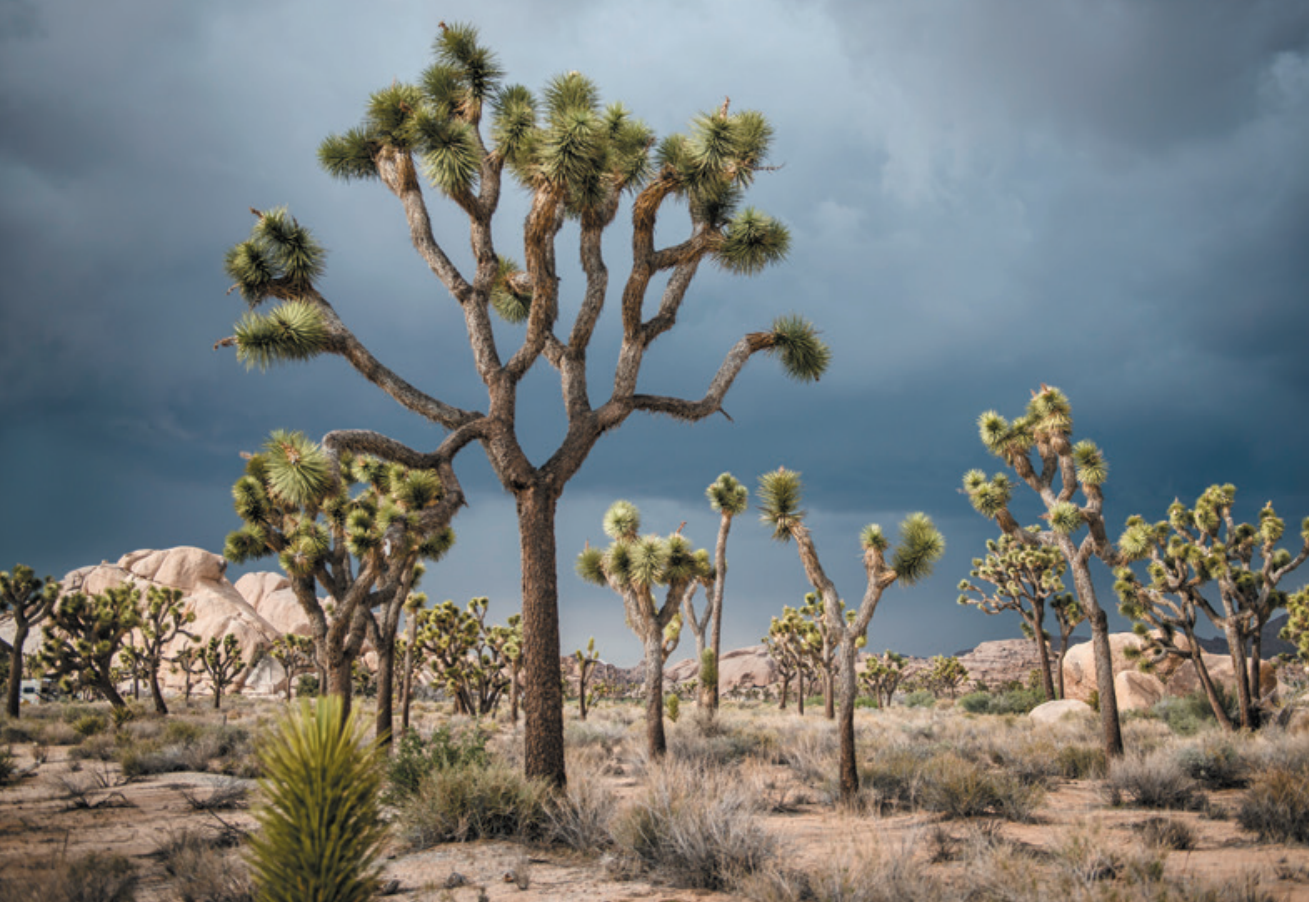

The Joshua tree (Yucca brevifolia) is one of dozens of species in the Project Baseline seed bank.

\section{BY DANIEL CRESSEY}

$\mathrm{I}$ a vault kept at $-18^{\circ} \mathrm{C}$ in Fort Collins, Colorado, more than 5 million seeds now lie frozen in time - destined to wait for up to 50 years until evolutionary scientists earn permission to experiment with them.

Unlike most seed banks, which aim to protect biological diversity, Project Baseline is designed to enable precise, controlled studies of how plants are evolving in response to climate change and environmental degradation. Taken from around 250 locations across the continental United States and stored at a US Department of Agriculture facility, the seeds represent some 60 species.

Scientists began collecting the seeds in earnest in 2012, backed by a US\$1.3-million grant from the US National Science Foundation (NSF). They took care to gather specimens in a wide variety of environments and to cover a multitude of plant types, from the humble radish (Raphanus sativus) to the iconic Joshua tree (Yucca brevifolia).
The collection phase is now complete, says project lead investigator Julie Etterson, a plant biologist at the University of Minnesota Duluth. Earlier this year, she and her colleagues published a paper in the American Journal of Botany introducing Project Baseline to the community (J. R. Etterson et al. Am. J. Bot. 103, 164-173; 2016).

To find out whether species are evolving in response to human pressures such as climate change, scientists have previously observed differences in similar species living at various sites or studied one site over time, charting how plants change along with the site. But it can be difficult to distinguish between changes that are the result of evolution - the selection of traits over generations owing to the survival of certain individuals - and those that are due to the ability of individual plants to react to a changing environment, called plasticity.

Project Baseline will allow scientists to grow stored seeds side by side with those from plants that were left to evolve, in identical conditions: any differences can then be attributed to evolution.

"I think it's terrific," says Richard Lenski, who studies evolution in bacteria at Michigan State University in East Lansing. "To some extent, museum specimens and even natural seed banks allow scientists to make these comparisons today, but not in the in-depth, systematic and well-thought-out way that this project will allow."

Questions that could be explored include whether the early flowering observed in some plants in conjunction with global warming is attributable to evolution or plasticity, and how rates of evolution vary between different populations of the same species. Genetic sequencing will help researchers to discover which genes are linked to traits that have been selected for. It could also test predictions, such as that low genetic variation increases extinction rates, and that evolution occurs through many small genetic changes rather than a few large ones. "The list of hypotheses is really only limited by the imagination," says Etterson.

\section{BACK TO LIFE}

Project Baseline breathes new life into a field known as resurrection ecology. Its best-known experiments hatched invertebrate eggs that had been naturally preserved in lake sediments, and compared the offspring with those of recently laid eggs. A now-classic example, from the lab of environmental scientist Nelson Hairston at Cornell University in Ithaca, New York, used sediments from Lake Constance in central Europe to prove that water fleas (Daphnia galeata) had rapidly evolved tolerance for toxic cyanobacteria (N. G. Hairston et al. Nature 401, 446; 1999).

Because Project Baseline actively lays the foundation for future research, rather than relying on what nature has sequestered in the past, it is a "kind of visionary project", says Hairston.

It does assume that there will be observable environmental changes at the sites from which the seeds were collected, notes Charles Kerfoot, a biologist at Michigan Technological University in Houghton and another pioneer in resurrection ecology. But such differences are guaranteed because of climate change, he says: "This is a group that's not in denial."

Exactly when the scientists will wake the seeds in the vault from stasis is less clear. Project Baseline's first call for proposals to work with the specimens is planned for 2018, and Etterson says that the first seeds could be planted as soon as 2020. She hopes to get at least one use out of the project herself before she retires.

The timescales are long compared with both the average evolution study and the average NSF grant, say researchers, but that makes Project Baseline special. "This is really different," says Samuel Scheiner, the director of the NSF programme that funded the project, "but exactly what we need to do if we're going to study global change." - 